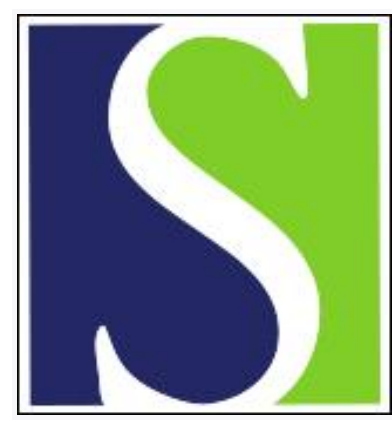

Scand J Work Environ Health 1997;23(4):241-242

https://doi.org/10.5271/sjweh.216

Issue date: Aug 1997

\title{
Cardiovascular disease and shift work
}

by Åkerstedt T, Knutsson A

The following articles refer to this text: 2001;27(3):161-213;

2002;28(1):64-71

This article in PubMed: www.ncbi.nlm.nih.gov/pubmed/9322814

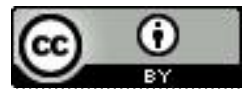




\section{Cardiovascular disease and shift work}

Shift work has "traditionally" been associated with disturbed sleep, wakefulness, and gastrointestinal problems (1). Links to cardiovascular disease have not been supported in the literature (1). However, relatively recently, Scandinavian studies found such connections, with relative risks of around 1.5 , and suggested that earlier studies might have overlooked existing relationships (2). Since then, several new studies have added to the weight of evidence (3-4) and have also found the relation to hold also for women (5). Although the relative risk is rather low, the exposure prevalence in modern society is about $20 \%$, which yields a population etiologic fraction of $7 \%(6)$ and makes shift work one of the major work environment factors related to cardiovascular disease.

However, even if the evidence clearly indicates that shift work may contribute to the development of cardiovascular disease, we still do not know the mechanism behind this effect. Thus factors in the work or life situation, apart from shift work itself but associated with it, may be responsible for the effect. Smoking could be such a factor, but it can probably be ruled out since it has usually been properly controlled for in most studies. One possible confounder, however, is the work task, which can be responsible for cardiovascular effects since it is felt that shift workers have heavier work, experience more stress, have less influence on work, and have a lower level of education than day workers. However, we still lack studies that empirically demonstrate that these disadvantages exist among shift workers and that such disadvantages would constitute the link to the excess cardiovascular risk for shift workers. The study in the present issue by Tenkanen et al (7) suggests that stress or strain (stress in relation to influence) is not responsible, but that shift work exerts an independent influence on cardiovascular risk. This may turn out to be a very important observation if confirmed.

Another possible link is the type of food consumed by shift workers. Anecdotally it seems to be less than optimal but there is little empirical evidence available on the subject (8). One might also speculate that the metabolic response to food intake varies depending on circadian phase, although this possibility has not yet been established. Sleep loss incurred because of shift work (9) is another factor that can possibly affect cardiovascular risk factors since sleep involves major metabolic and immunologic changes. The existence of the link remains to be demonstrated, however.

Obviously, the possible link between shift work and cardiovascular disease needs to be established in longitudinal studies with experimental intervention - there is a striking lack of such studies. One frequent problem in this respect is excessive statistical control. Thus, for example, lipid and blood pressure levels are frequently "controlled for" in many studies, despite the fact that they may be part of the connections between shift work and cardiovascular diseases. Since such approaches can cloud the issue of causation, studies are needed that keep "behavior" (stress, disturbed sleep) separate from intervening mechanisms (eg, lipids, blood pressure) when attempts are made to predict end points such as infarction or other forms of cardiovascular disease.

A final point is the absence of data on the cardiovascular effects of specific aspects of shift work, such as permanent night work versus alternating night and day work, roosters versus regular shift work, early versus late shift changing times, long versus short shifts, clockwise versus counterclockwise rotation, compressed versus expanded shift cycles, reduced total workhours, sleep on the work premises, and the like. The rapidly expanding "24-hour society" will require answers to many of these issues in order to provide workhour arrangements with as little health impact as possible; particularly since the new "Work Hour Directive" of the European Union contains no direct limitation of the use of night work in worklife. 


\section{References}

1. Harrington JM. Shift work and health: a critical review of the literature. London: Her Majesty's Stationery Office, 1978.

2. Åkerstedt T, Knutsson A, Alfredsson L, Theorell T. Shift work and cardiovascular disease. Scand J Work Environ Health $1984 ; 10: 408-414$.

3. Knutsson A, Åkerstedt T, Jonsson BG, Orth-Gomér K. Increased risk of ischemic heart disease in shift workers. Lancet $1986 ; 2: 86-92$.

4. Tüchsen F. Working hours and ischaemic heart disease in Danish men: a 4-year cohort study of hospitalization. Int J Epidemiol 1993;2:215-21.

5. Kawachi I, Colditz G, Stampfer M, Willett WC, Manson JE, Speizer FE, et al. Prospective study of shift work and risk of coronary heart desease in women. Circulation 1995;9:21-5.

6. Kristensen TS. Cardiovascular diseases and the work environment. Scand J Work Environ Health 1989;15:165 - 179.

7. Tenkanen L, Sjöblom T, Kalimo R, Alikoski T, Härmä M. Shift work, occupation and coronary heart disease over a 6-year period. Scand J Work Environ Health 1997;23(4):257-65.

8. Lennernäs M, Akerstedt T, Hambraeus L. Shift related dietary intake in day- and shift workers. Appetite 1995;25:253265.

9. Åkerstedt T. Work hours, sleepiness and the mechanism. J Sleep Res 1995;4 suppl 2:15-22.

\section{Torbjörn Åkerstedt, 'A Ander Knutsson²}

1 IPM \& Department of Public Health, Box 230

Karolinska Institute, S-171 77 Stockholm, Sweden

E-mail: torbjorn.akerstedt@ipm.ki.se

2 Department of Occupational and Environmental Medicine

University of Umeå, Umeå, Sweden 